\title{
IMÁGENES DE JÓVENES, CULTURAS JUVENILES Y ESCOLARES EN PROFESORES DE EDUCACIÓN MEDIA
}

\author{
RAÚl ZARZURI CORTÉS*
}

\begin{abstract}
RESUMEN
La finalidad de este artículo es entregar una aproximación a los «imaginarios» que tienen los profesores de colegios municipalizados, particulares subvencionados y particulares, respecto de sus estudiantes, sus culturas y la cultura escolar que ellos portan al interior de las escuelas. Es parte de una investigación exploratoria, que buscaba indagar en las posibilidades de integración de las culturas juveniles a las culturas escolares, particularmente en el espacio llamado liceo o escuela secundaria. Para dar cuenta de esto, fue necesario introducirse en los imaginarios que construyen los profesores sobre los jóvenes, las culturas juveniles y las culturas escolares.

Así, este artículo se propone describir esos «imaginarios», intentando acceder a los matices existentes, para identificar las tensiones que emergen a partir de las construcciones que se realizan respecto de las culturas que se investigaron y sus posibilidades de integración y comprensión. Se cierra el artículo, con un ejercicio interpretativo, que permite entender la información producida desde las categorías de «prejuicios juveniles» y la cuestión de «género»; la inexistencia de una visión clara por parte de los profesores de lo que son las culturas juveniles; como la idea de que «el profesor nunca ha sido joven» $y$, algunas metáforas de la escuela.
\end{abstract}

PALABRAS CLAVE: PROFESORES, IMAGINARIOS JUVENILES, CULTURA JUVENIL Y ESCOLAR

* Chileno, Sociólogo, Investigador y Coordinador de Investigación en el Centro de Estudios Sociales y de Opinión Pública (CESOP) de la Universidad Central de Chile. Investigador del Centro de Estudios Socioculturales (CESC). Actualmente es parte del proyecto Anillo Juventudes (CONICYT) sobre transformaciones de la juventud chilena, y este artículo forma parte de ese proyecto. E-Mail: rzarzuri@gmail.com.

El presente artículo es parte de la tesis que permitió obtener el grado de Magíster en Antropología y Desarrollo cursada en la Universidad de Chile: «Tensiones y desafíos en las posibilidades de integración de las culturas juveniles a las culturas escolares. visiones desde los profesores». 


\title{
IMAGENS DE JOVENS, CULTURAS JUVENIS E ESCOLARES EM PROFESSORES DE ENSINO MÉDIO
}

\begin{abstract}
RESUMO
O objetivo deste artigo é produzir uma aproximação aos «imaginários» que professores de escolas municipalizadas, privadas subvencionadas e privadas têm de seus alunos, suas culturas e da cultura escolar que estes levam para a escola . Tratase de parte de um estudo exploratório que buscou investigar as possibilidades de integração das culturas juvenis e culturas escolares, especialmente no espeço denominado liceu ou escola secundária. Para este propósito, foi necessário investigar os imaginários que os professores constroem sobre os jovens, as culturas juvenis e as culturas escolares.

Portanto, este artigo descreve estes «imaginários», tentando compreender os matizes existentes, para identificar as tensões que emergem das construções em relação às culturas investigadas e seu potencial para a integração e compreensão. $\mathrm{O}$ artigo temina com um exercício interpretativo que permite entender a informação produzida a partir das seguintes categorias: «preconceitos juvenis e a questão de gênero»; a inexistência de uma visão clara dos professores sobre culturas juvenis; como a ideia de que «o professor nunca foi jovem» e algumas metáforas da escola.
\end{abstract}

\section{PALAVRAS CHAVE: PROFESSORES, REPRESENTAÇÕES JUVENIS, CULTURA JUVENIL E ESCOLAR}

\section{IMAGES OF YOUTH, JUVENILE AND SCHOOL CULTURE IN TEACHERS OF SECONDARY EDUCATION}

\begin{abstract}
The purpose of this article is to give an approximation to the «imaginary ones» that teachers have of municipal schools, particular subsidized and private, to their students, their cultures and the school culture they carry into schools. It is part of an exploratory study that sought to investigate the possibilities of integration of youth cultures at school cultures, particularly in the area called high-school or secondary school. To account for this, it was necessary to enter in the imaginary ones that teachers built on youth, youth cultures and school cultures.

This way, this article tries to describe these «imaginary ones», trying to accede to the existing shades, to identify the tensions that emerge from the constructions that realize respect of the cultures that were investigated and his possibilities of integration and comprehension. The article is closed, with an interpretive exercise, which allows to understand the information produced from the categories of: «juvenile prejudices and the question of gender»; the nonexistence of a clear vision on the part of the teachers of what they are the juvenile cultures; as the idea of that «the teacher has never been young» and, some metaphors of the school.
\end{abstract}




\section{INTRODUCCIÓN}

PARA NADIE ES un misterio que hoy la escuela se encuentra tensionada por una serie de factores. Uno de ellos son los procesos de masificación acelerada de la escuela que se manifiestan a partir de mediados del siglo XX. Así, la masificación de la oferta escolar modifica una serie de relaciones internas en el funcionamiento de las escuelas, lo que genera que cuando «ingresan los que tradicionalmente estaban excluidos», la forma y características del alumnado se transforma. En suma, y como señala Tenti «los grandes cambios en los modos de producción y en la estructura social y familiar, las transformaciones en el plano de las instancias de producción y difusión de significados afectan profundamente los procesos de construcción de las subjetividades» (2000).

Junto con esto, y dado los procesos de globalización y el impacto de las tecnologías de información y comunicación, se origina un nuevo espacio cultural, un nuevo «sensorium» —en términos de Martín Barbero el cual a su vez sigue a Benjamin -, lo cual implica asistir a un desplazamiento de lo que se ha denominado una oralidad primaria basada en la escritura, el texto escrito, a una oralidad secundaria (Ong, 1987, en Martín-Barbero, 1998) que se manifiesta en una visualidad electrónica que permite que emerja esta nueva era de lo sensible. Esta nueva oralidad, se muestra fuertemente en las nuevas tecnologías de comunicación; es la que provoca el des-ordenamiento cultural, ya que «rompe el orden de las secuencias que en forma de etapas/edades organizaban el escalonado proceso del aprendizaje ligado a la lectura y las jerarquías en que ésta se apoya» (Martín-Barbero, 1998). Esto implica que los jóvenes se sienten cada vez más identificados con estas nuevas formas fragmentarias de cultura, con esta nueva cultura digital/audiovisual característica de los medios modernos que origina una nueva cultura: la cultura digital o de medios.

Así, la nueva «morfología social de los alumnos» que señala Tenti, junto con la identificación de los jóvenes con culturas digitales o de medios como señala Barbero, han producido un nuevo tipo de joven que hoy habita el espacio que llamamos escuela. Esto nos permite señalar, que estamos en presencia de un nuevo sujeto joven, de una nueva generación de jóvenes, distinta a las generaciones anteriores de adultos, que rompen con antiguas prácticas culturales: «[...] vemos emerger una generación 'cuyos sujetos no se constituyen a partir de identificaciones con figuras, estilos y prácticas de 
añejas tradiciones que definen la cultura sino a partir de la conexióndesconexión (juegos de interfaz) con las tecnologías'. Nos encontramos ante sujetos dotados de una 'plasticidad neuronal' y elasticidad cultural que, aunque se asemeja a una falta de forma, es más bien apertura a muy diversas formas, camaleónica adaptación a los más diversos contextos y una enorme facilidad de 'idioma' del video y del computador, esto es para entrar y manejarse en la complejidad de las redes informáticas» (Martín-Barbero \& Rey, 1999).

Todo este nuevo contexto genera tensiones, ya que precisamente el mundo adulto al interior de la escuela aún funcionan con el viejo paradigma que homogeniza a los jóvenes, por ejemplo utilizando la categoría o condición de estudiante/alumno, desconociendo la diversidad de jóvenes y culturas existente hoy día en las aulas.

La tensión existente, entre el viejo paradigma homogeneizador y el nuevo, ha sido trabajada por varios autores, entre ellos Dubet y Martucelli, particularmente en lo relacionado con lo que se denomina «la crisis de la escuela». Para ellos, la escuela ha sido tradicionalmente entendida como un molde cultural que permite a los alumnos interiorizar normas y valores, ignorando que la experiencia no es unidireccional, sino que está en primer lugar, condicionada y construida in vivo por los actores presentes. Esta afirmación subyace en la creencia de que el alumno tiene y ejerce poder en tanto maneja las dinámicas de integración e interiorización social, las cuales a su vez están determinadas por su propia subjetividad. El juego de roles que surge de esta relación social y la masificación escolar a mediados del siglo XX, sumado a la crisis que atraviesa la sociedad y que también se manifiesta en la escuela a través de la falta de certezas y control, ha generado en la población y en los sujetos una constante sensación de incertidumbre que no solo ha minado la seguridad de la escuela, sino que ha agotado gran parte de los recursos, estructuras y roles de la institución educativa. En este sentido «[...] la imagen dominante es la de una crisis continua del sistema educativo, debida al derrumbe de las antiguas formas pedagógicas, a la caída del nivel, al debilitamiento del prestigio de los docentes, a la competencia de la cultura escolar y de culturas de masa más seductoras y más poderosas, a la llegada de nuevos alumnos inadaptados [...]» (1988). Esto ha llevado a plantearse nuevas preguntas a la escuela, y a entenderla como una organización «[...] de fronteras flotantes, de objetivos cada vez redefinidos, de relaciones cada vez reconstruidas; ya no es reductible a la forma burocrática general que la encierra» (1988). Por lo tanto, 
se asiste a un agotamiento de su cultura y sus promesas, lo cual construye una tipo de organización desestabilizada, lo que da cuenta de un momento de fuertes transformaciones pedagógicas que no tienen una dirección determinada.

Esta situación, pone de manifiesto según los autores otro problema. La escuela no ha sido capaz de considerar la subjetividad y el empoderamiento del joven, a partir de la cultura juvenil, como parte necesaria del sistema. Así, «Mientras la sociedad francesa ve instalarse un tiempo de la juventud y una cultura adolescente, [...], la escuela se preserva ampliamente de estas mutaciones por la separación de sexos, el mantenimiento de la disciplina escolar y la distancia entre jóvenes y adultos» (1988).

Hay que señalar, que la propuesta de los autores reconoce la fuerza impositiva de la cultura escolar, pero reivindican la autonomía del sujeto en tanto consideran que su propia acción construye identidad y aporta al espacio social a través de su hacer cotidiano. En este sentido la socialización está condicionada por un proceso de comprensión individual previo que sirve de vínculo entre el alumno y su alrededor. En el fondo se trata de reconocer en el sujeto la capacidad estratégica de organizar lo que interioriza como un acto autónomo - $\mathrm{y}$ a ratos consciente - en donde se define a sí mismo y adopta un lugar desde donde posicionarse.

De esta forma, la escuela - y también los profesores-, no entienden que las nuevas generaciones son portadoras de culturas diversas, fragmentadas, abiertas, flexibles, móviles, inestables, entre otras cosas y, que no se conectan con la cultura escolar que tiende más a la homogeneidad, sistematicidad, continuidad, coherencia y al orden. Así, la escuela se convierte a menudo en una frontera donde se encuentra y enfrentan diversos universos culturales, convirtiéndose en un espacio vacío o en un «No Lugar» - siguiendo a Marc Auge- para las culturas y lenguajes juveniles, ya que esta intenta evitar la penetración de otras culturas aislando a la escuela. Por otra parte, se niega e invalida el conocimiento o saberes que portan esas culturas ya que estos no están consagrados en los programas escolares. La escuela entonces, aparece como un lugar que deja de constituir certidumbres y certezas. Esto responde, como bien expresa Reguillo (2000), a que hoy en día es posible ver que la escuela continúa al margen de los procesos de constitución sociocultural de las identidades juveniles, siendo sobrepasada por una cultura que aún no logra entender, ni tampoco quiere hacer el intento de conocerla. 
Estas nuevas formas de expresión son precisamente las que instituciones escolares se empeñan en dejar fuera del Establecimiento. José Manuel Valenzuela refiriéndose en particular al caso mexicano sostiene que «[...] la educación escolar no debe considerar que la vida está en otra parte y que los grandes problemas y asuntos que inciden en la vida de los niños y jóvenes no son asuntos de las aulas [...] como si la vida estuviera en otra parte y se iniciara cuando ellos dejan las aulas escolares» (2005). Este tipo de prácticas refuerzan lo que el autor ha denominado encapsulamiento escolar.

\section{IMÁGENES}

Una constatación que se puede hacer respecto de la investigación sobre culturas juveniles y culturas escolares, es que la investigación sobre la relación entre estos dos conceptos es todavía incipiente en Chile. De hecho, si se revisa la Base de Datos del Fondo Nacional de Desarrollo Científico y Tecnológico, no se encuentran estudios directamente relacionados, pero tampoco hay una abundancia de estudios sobre las culturas escolares y las culturas juveniles. Entonces, lo poco y nada que se escribe, es a nivel de artículos en revistas de educación u otras, ${ }^{2}$ o espacios institucionales de centros de estudios ${ }^{3}$ derivados tangencialmente de otros estudios que no abordan directamente esta temática, siendo estudios sobre valores juveniles, sobre la conformación del ser estudiantes, sexualidad, etcétera.

A pesar de esto, los escasos estudios que se tienen sobre la relación cultura juvenil y cultura escolar, nos señalan que la incorporación de las culturas juveniles a la cultura escolar es un proceso — que en el mejor de los casos se encuentra inconcluso y permanentemente en tensión-, principalmente debido a los imaginarios o imágenes que tienen los profesores respecto de sus alumno o estudiantes y de las prácticas culturales que desarrollan, lo cual supone la construcción y existencia de dos mundos desvinculados, con encuentros/desencuentros que potencian relaciones conflictivas al interior del espacio escolar, las cuales se expresan no solo en la marginación, estigmatización

2 Por ejemplo: Oyarzún, 2000; Bellei, 2000; Molina y Sandoval, 2006; Cerda, Assael, Ceballos y Sepúlveda, 2000; Duarte, 2002; Edward, 1995.

3 Ver los documentos que ha publicado el Centro de Estudios SocioCulturales (CESC): Benavente y Figueroa, 2005 y Contreras, 2005. 
y los prejuicios de parte de muchos docentes hacia sus jóvenes revelando sus desconfianzas a estas manifestaciones culturales, sino que en ocasiones pueden también expresarse en maltrato psicológico e incluso físico respecto de los alumnos hacia sus profesores y viceversa.

A continuación, se presentan algunas de las imágenes que han sido rescatadas de los discursos de diferentes profesores entrevistados.

\section{a) Solos, abandonados, carenciados e infantiles}

No resulta sencillo solicitar a los profesores que describan o caractericen a sus estudiantes. Una primera cuestión que aparece dice relación con un diagnóstico que remite a las transformaciones de nuestro país en el tránsito vertiginoso a una sociedad plenamente moderna. Así, un primer concepto que emerge y es transversal en los discursos de los profesores es que los jóvenes están muy solos, o sea, la imagen que se tiene, es de un 'sujeto solitario', lo cual, es una caracterización que no distingue estrato social.

Ellos se manejan solos en un montón de situaciones, pero, pero hay una suerte de soledad, que recorre nuestro alumnado. Yo como estoy estudiando principalmente el vínculo padre-mamá, estoy muy afectada por eso (Colegio Particular).

Las formas que los profesores tienen para explicar el porqué de esto, es la crisis de las instituciones como la familia. De hecho, la crítica a esta institución es fuerte, porque en opinión de ellos no está cumpliendo el rol que se supone debe cumplir - contención, internalización de normas, afectos - y esto, evidentemente afecta el rol de los profesores y las formas de interactuar con sus alumnos. Así, independientemente del estrato socioeconómico, para muchos docentes la familia no hace acto de presencia en la vida de los jóvenes, dejando a estos en el abandono; transitando la vida en forma solitaria, permitiendo de este modo, la construcción de una cierta «autonomía juvenil por deficiencia».

Las explicaciones a esto van desde la disolución de la familia tradicional ya sea porque se está frente a situaciones de separación, por lo tanto los jóvenes ya no viven en la denominada «familia típica»:

[...] ese abandono puede ser principalmente porque la constitución familiar no es la típica [...] o falta la madre o falta el padre [...] o simplemente viven con otros familiares y creo que simplemente ahí hay un desarraigo (Colegio Subvencionado). 
Otro eje explicativo, es entender el abandono debido a la excesiva carga laboral que enfrentan los padres. Es interesante esto, porque precisamente permite comprender que ciertas situaciones que afectan a los jóvenes se manifiestan para todos, no importando su procedencia. De hecho, los efectos serían los mismos en los jóvenes, sea porque los padres llegan cansados a la casa del trabajo y no pueden establecer ningún tipo de contacto con sus hijos - jornadas extensas de padres en sectores populares en busca de la subsistencia-, o porque, como señalan los profesores del colegio particular, los padres están tan compenetrados en la busca del éxito, que la inversión que realizan de su tiempo - más horas trabajando, viajes entre otras cosas- les impide también generar vínculos con sus hijos.

O sea, tenemos que pensar en los padres de ellos que llegan cansados, que trabajan como asesoras domésticas, que son obreros, que están tan, tan desencantados como los cabros, como les pasa a los cabros con la sociedad en la que viven (Colegio Municipalizado).

Y tampoco son de papás que se vayan a encontrar a la hora de almuerzo, o que se vayan a encontrar tipo siete de la tarde, y estén todos juntos... no. O sea, con suerte, los ven en la noche, si es que ellos no han salido también. Porque ocupan mucho tiempo con los amigos. Entonces los papás, hay veces que hay niños que no ven a sus papás prácticamente en toda la semana (Colegio Particular).

Desde esta caracterización el salto a la construcción de imágenes de jóvenes con carencias efectivas es inmediato; causal podríamos decir. Demás está decir que los profesores se sienten afectados por esta situación, ya que para ellos no es algo que hayan experimentado. Nos referimos al rompimiento del núcleo familiar cuando eran niños o jóvenes. Como señala un profesor.

Uno vivió cerca de sus padres siempre. Entonces, a mí me duele mucho la vida que están teniendo los jóvenes de hoy. No todos, afortunadamente, pero un porcentaje alto de nuestros niños (Colegio Particular).

Esta situación que se conecta con las vivencias de los profesores, en muchos casos los lleva a ver a sus alumnos como niños con necesidades afectivas, lo cual hace emerger la imagen del «joven incomprendido», del «joven carenciado» que visibiliza un «joven ego», 
aquel que necesita de atención afectiva, cuestión que construye —en opinión de algunos profesores-, un sujeto que necesita que todo gire alrededor de ellos. Esto llevará a los profesores a un proceso que podríamos llamar de infantilización de sus alumnos.

Este proceso de infantilización, en muchos casos está relacionado con una característica central de los jóvenes: «la inquietud», que al parecer debería ser leída como movilización o movilidad en un doble sentido. La primera refiere a una «inquietud», que tiene que ver con desplazamientos que remiten a actitudes conductuales dentro del espacio escolar (particularmente la sala de clases) y la segunda, podría referirse a «inquietudes», que apuntan a sed de conocimientos, cualesquiera que sean estos. Así, las imágenes de «caballitos locos», «animalitos», «monos» o «aguaguados» entre otras cosas aparecen nítidamente y poblan los imaginarios de los profesores, lo cual puede ser sintetizado en el concepto de «cabro chico con carencia afectiva».

[...] tienen tanta inquietud que son caballitos locos y se disparan. [...]. Animalitos [...] Lo que pasa es que hay cabros de primero que son cansadores, son muy cansadores, donde son tan chicos y ahí gritan y parecen monos [...] (Colegio Municipalizado).

Yo los veo y converso con ellos de algunas cosas. De las reacciones que tienen, son pero aguaguados total, y eso también tiene que ver con la falta de afecto. Porque reaccionan como regalones (Colegio Particular).

\section{b) Tensiones con la carencia: «capaces», «aperrados» y «críticos»}

Lo anterior supone un proceso de etiquetamiento sobre los alumnos, claro está que para este caso, de una forma más o menos benigna: «son cabros chicos», pero que no deja de ser, ya que el imaginario es de unas personas infantilizadas y minusvaloradas, que no podrán tener entonces, capacidad de relacionarse de igual a igual con el mundo adulto del colegio.

Sin embargo, habría que señalar que estos etiquetamiento reflejan contradicciones en los profesores que no son menores. Por ejemplo, entienden que los jóvenes de hoy en día tienen más autonomía - que ya denominamos 'autonomía por deficiencia'-, cuestión que ellos leen en algunos casos como tener cierto grado de madurez, pero critican que sean contradictorios en su accionar, particularmen- 
te cuando se expresan culturalmente, ya sea por referencias a sus «ídolos», o a prácticas asociadas a las drogas y carrete.

Pero mira las contradicciones eso que dices de que por un lado, salen, carretean, tienen auto, y por otro lado tú les preguntas, el otro día comentábamos, escribe una composición sobre alguien que admire, y ponen a Hanna Monthana, en cuarto medio... entonces es una contradicción terrible. Hanna Monthana [...] (Colegio Particular).

[...] cuando uno pasa al tema de drogas, por ejemplo, y uno le dice, las consecuencias, la drogadicción, y todos hacen así con la cabeza [gesto afirmativo]. Y después cuando no sé, estamos en consejo de curso, forman sus grupos, conversan, lo que hicieron en los carretes, y ahí uno se da cuenta que es totalmente distinta la realidad (Colegio Subvencionado).

[...] se rompen los antiguos estereotipos que uno tenía, que [...] no sé, que era deportista $[\ldots]$ no se copeteaban, y no fumaban marihuana y todas esas cosas, y la verdad es que no es tan así (Colegio particular).

A pesar de eso, y nuevamente en forma contradictoria, los profesores rescatan en sus alumnos, categorías más benignas como «capaces», «aperrados», «críticos», «inteligentes», etiquetamientos generosamente positivos, cuestión que se encuentra en todos los profesores entrevistados.

Yo los admiro en el sentido de que encuentro de que son muy capaces. Muy capaces y muy aperrados cuando ellos quieren hacer cosas. Eh [...] me gusta, que si bien es cierto no la mayoría, pero [...] O sea no todos, pero la gran mayoría, son capaces de pensar por sí mismos, encuentro que no $[\ldots]$ (Colegio Particular).

Sin embargo, estás características de los alumnos trae consecuencia para los profesores que tensionan su actividad docente. La caracterización antes realizada supone para los profesores un esfuerzo, una demanda en el aspecto laboral como educadores, que en muchos casos lleva a situaciones de agotamiento. Sin embargo, esto también supone desafíos y ciertas gratificaciones que de alguna forma, deberían mitigar esta situación.

Encuentro que son cabros que $[\ldots]$ críticos, que muchas veces se nos produce un agote espantoso, porque tenemos que saber manejar eso. Y 
es difícil. Cuando tú trabajas con adolescentes muy inteligentes y críticos. Tú tienes que ser muy crítica e inteligente también. Entonces eso es un tema de desgaste constante en nuestra carrera (Colegio Particular).

Son cansadores pero, bueno, también tienen su lazo de afectividad, que al final terminan enganchando contigo (Colegio Municipalizado).

\section{c) El joven camaleónico}

Otra de las imágenes que emerge como una característica de interés respecto de los jóvenes, es una cierta capacidad de desdoblamiento o mejor dicho, de una capacidad de manejo del oficio de joven y de alumnolestudiante, que supone saber cómo actuar los roles que portan como sujetos. Esto es visto como una capacidad de mimetizarse.

Surge entonces una imagen, la del camaleón: «joven camaleón». Aquel joven que cambia de color según el entorno donde está. Pues bien, los jóvenes tienen esa misma capacidad, cuya función es compatibilizar los roles esperados en cada uno de los espacios culturales donde se mueven: el colegio con su cultura y «la calle», cuestión que también aparece referido al concepto de «jóvenes duales».

Como señala un profesor de colegio subvencionado - pero que refleja más o menos a los otros profesores-, los jóvenes juegan con sus roles y sus estéticas (adscripciones identitarias «tribales» o escolares), las cuales van modificando de acuerdo al grado de aproximación al espacio escolar o al alejamiento de este.

[...] el chico viene, vestido de punk, con gorros, con mochilas, medias, el pantalón abajo, y a medida que se va acercando [a la escuela], se va 'amononando', se va arreglando [para ser estudiante]. Y después cuando hace el regreso, es al revés, a medida que se va acercando a su sector, se va de nuevo mimetizando [para ser joven] (Colegio Subvencionado).

Es interesante este punto, porque en el fondo lo que se vislumbra, es la capacidad de jugar con los roles; de adaptarse; de ser plástico en su accionar, cuestión que nos lleva a ver a estos jóvenes como actores que manejan a la perfección sus papeles o roles a desarrollar en los espacios por los cuales transitan y que les permite insertarse más o menos exitosamente en los distintos ambientes culturales en los que se desenvuelven. Por otra parte, esto también puede ser visto 
como una movilidad de identidades dentro del mismo joven, ya que la forma de ser y actuar dentro y fuera del colegio, son radicalmente diferentes

\section{d) El joven tecnologizado y exhibicionista}

No cabe duda que hoy en día, los jóvenes están tecnologizados, son «nativos digitales», como diría Prensky (2000). Los profesores se dan cuenta de esto, pero no hay una forma común para enfrentarlo, en relación a las consecuencias que trae esto. Un profesor de Liceo municipalizado, señala que hoy la tecnología y los contenidos están en todos lados; al alcance de todos los jóvenes, lo cual permite que sean más independientes a la hora de buscar información por ejemplo. Incluso, plantea entre líneas, el sentido de una institución clave de la oralidad primaria (asociado a la lectura) como es la biblioteca.

Hay varias cosas, primero el tema de la tecnología. O sea, si hablamos de esto de [...] si yo quería saber cómo funciona algo me tenía que ir a una biblioteca, ahora los contenidos están en todos lados. ¿Te fijai? (sic) El tema de la tecnología está. Entonces como hay más acceso a la información, muchas veces los chiquillos, no todos, son más independientes [...] (Colegio Municipalizado).

Así, la tecnología genera independencia en los jóvenes. Sin embargo, esta visión positiva es vista por los profesores de sector alto - aunque habría que señalar que algo de esto hay en todos los profesorescomo algo preocupante, particularmente en lo relativo a lo que genera en los jóvenes: el afán de mostrarse, de exhibirse y así estar informados de los otros y que estos también se informen. La idea de mostrarse que subyace a estos comentarios, se liga al concepto de lo «desechable», en todos los ámbitos. Todo es desechable para los jóvenes piensan los profesores.

[...] además hablando un poco de cultura televisiva, que es lo más rápido que llega a ellos, internet, hoy día todo es desechable, por eso las relaciones también son desechables para ellos, todo es mostrar, no importa que, no hay mucho... tiempo, o ganas, o intenciones de cultivarse por dentro. Todo tiene que mostrarse. Todas estas cosas de facebook de lo que sea, todo es mostrar. Y pasan mucho tiempo, antes no sé, a una la retaban porque ya estaba hablando mucho rato por teléfono, él teléfono de la casa, pero ahora pasan todos metidos en el face- 
book, y saben de la vida de todos, oye. Esta estaba acá, estaba allá, y uno piensa, o tendía a pensar, antes que conociese esto, que a lo mejor son íntimos amigos, pero es mentira, o sea cada uno se mete en la vida de cada cual, y esta cosa de exhibición [...] (Colegio Particular).

La exhibición denota para los docentes por una parte, una construcción de sujeto que no reflexiona mucho y que transita como estas tecnologías, rápido; mutando. Habría que señalar, que las tecnologías tienen precisamente esas características, avanzan muy rápidamente dejando obsoletas en cuestión de meses aquello que era novedoso; por lo tanto, evidentemente la instalación de «lo deseable», tiene sentido. Demás está decir que una analogía que se puede utilizar respecto de esto, es comparar a internet con una vitrina de una tienda, por lo tanto, como vitrina, tiene que renovarse cada cierto tiempo. Evidentemente, que esto podríamos conectarlos también, con el tema de las identidades y las interpretaciones que desde teorías que se podrían denominar (post)modernas, al asumir que actualmente y particularmente en los jóvenes, son móviles; «desechables».

Es interesante rescatar al interior del discurso la contraposición con el concepto de «cultivarse por dentro». Quizás esto es una reminiscencia de «cultivarse espiritual e intelectualmente», lo cual lleva entonces, a que estas nuevas formas de transitar - por la vida, por internet - relacionadas con lo desechable, la rapidez, sean la base de la estructuración de los sujetos jóvenes actualmente.

Esto se puede ver, cuando los profesores del colegio particular se refieren a las relaciones afectivas y las relaciones sexuales que mantienen los jóvenes. Los discursos dejan entrever el carácter desechable de las cosas, como critica.

Un día yo les decía a las niñas: niñitas, ustedes se acuestan con el pololo porque están enamoradas. Pero, ¿cuántas veces se van a enamorar este año? Si en la edad de ustedes los amores son efímeros. Entonces, si tú te enamoras y te acuestas con un pololo, y al mes siguiente se acabó el pololeo y te acuestas con otro pololo, y en tres meses más te acuestas con otro pololo, vas a terminar marcada dentro del ámbito colegio, como que eres una fresca. Entonces, piensa antes de actuar. Reflexiona, piensa, trata de madurar esto que te estoy diciendo (Colegio Particular).

Ahora, habría que señalar, que detrás de esto evidentemente hay juicios valorativos respecto de los jóvenes que se enmarcan dentro 
de lo que se venía señalando: son todavía cabros chicos, inmaduros, independientes, pero sin límites, entre otras cosas. Los juicios, aunque en muchos casos no explícitos, son fuertes.

\section{ALGUNAS DISTINCIONES EN LA CONSTRUCCIÓN DE LOS JÓVENES}

Si bien, hasta ahora nos hemos referido a cuestiones que todos los jóvenes comparten en los imaginarios de los profesores, evidentemente que hay diferencias entre los jóvenes de acuerdo al espacio cultural que habitan. Por una parte tenemos a los jóvenes de los sectores altos que comparten una realidad totalmente distinta de los sectores «medios» o bajos. Respecto de ellos, los profesores señalan que este tipo de jóvenes tiene su futuro armado económica, social y culturalmente. Pero además, saben que van a entrar a la universidad que quieran, porque también tienen asegurado el puntaje que van a sacar. De eso hay seguridad plena y el colegio se encarga de habilitarlos para eso, cuestión que se corresponde con lo que pagan como mensualidad.

Por otra parte, este es un tipo de joven que tienen un deber ser muy fuerte y que a pesar de los déficit en las relaciones familiares, la mirada a los padres es fuerte como referente, especialmente en lo que concierne a la continuación de estudios en la universidad, donde el deber ser asociado a las profesiones del padre en particular es bastante fuerte. Según los profesores, muchos jóvenes van a escoger las carreras que ejercen sus papás, aunque no se sientan tan cómodos con eso.

Por otro lado, el resto de los jóvenes, pero particularmente los jóvenes que estudian en el liceo municipalizado, se encuentran en el lado opuesto. Provienen de hogares con bastantes carencias - si las comparamos con los jóvenes de estratos altos y medios-, con padres que tiene menor escolaridad, por lo tanto, en opinión de los profesores, no tienen internalizado que estudiar los puede ayudar a salir de esa situación. O sea, tener movilidad social ascendente.

$\mathrm{Si}$ bien esto es generalizado en los profesores y estructuran una imagen donde el colegio para este tipo de jóvenes es una obligación, matizan un poco esto integrando la categoría de desesperanza. Al parecer, la construcción de la obligación a ir al colegio, estaría mediada por esa desesperanza; una desesperanza que emerge — según los profesores - al ver como sus compañeros de otras generaciones no están trabajando en lo que estudiaron por ejemplo: 
[...] porque los chiquillos ven que sales de cuarto, no están ejerciendo lo que estudiaron, entonces como una suerte de [...]de que pa'qué [sic] nos preocupamos tanto, si al final igual van a terminar vendiendo helados, trabajando en un supermercado (Colegio Municipalizado).

Evidentemente, se estructura una realidad que no tiene la luminosidad de los jóvenes de sectores altos. Es un mundo opaco, clausurado, cerrado.

[...] entonces es un mundo, un mundo totalmente cerrado, o sea, no es que ellos sean cerrados sino que viven un mundo que es su población, su villa, liceo $-\mathrm{y}$ ni siquiera, ni siquiera han pensado en su vida que puede salir de ahí o hacer algo más de lo que es su entorno o ir a la universidad- (Colegio Municipalizado).

A pesar de esto, ¿qué podría unir a estos jóvenes tan diferentes entre sí? Una «unión en la diferencia», lo cual es paradójico. Por ejemplo, siendo realidades tan distintas, económicamente, culturalmente, ambos tipos de jóvenes viven en lo que se podría denominar ghettos, tanto a nivel espacial como simbólico. Por ejemplo, los profesores del colegio particular, señalan que este tipo de jóvenes jamás salen de sus límites establecidos en el sector oriente de la capital. Acá, al parecer, la barrera no es Plaza Italia, sino que está en lo que se ha llamado «la cota mil». Sin embargo esta misma realidad la viven los jóvenes de sectores populares, claro está que de otra manera. Al igual que los jóvenes de sectores populares, en muchos casos tienen pocas posibilidades de desplazarse fuera de los territorios en los que viven. Como señala una profesora:

[...] es que tienen que tomar en cuenta que el nivel socioeconómico, de hecho, y que en cuarto[...] que [...] también en el último cuarto, nunca han ido al centro de Santiago, [son jóvenes de] 17 y 18 años [...] no salen de su barrio (Colegio Municipalizado).

\section{LAS CULTURAS JUVENILES COMO UN OBJETO CULTURAL NO IDENTIFICADO}

Una de las cosas interesantes que deja ver el discurso de los profesores, y esto es una cuestión transversal, es que las culturas juveniles aparecen ante sus ojos como un Objeto Cultural No Identificado (OCNI), si parafraseamos a García Canclini (2000). 
Las culturas de los jóvenes son cosas no identificables por lo menos en dos sentidos. Primero, porque aparecen como raras, extrañas, lo cual remite a que son desconocidas para los profesores, no tienen conocimientos de ellas, y segundo, como no identificables en el sentido de que los profesores no pueden identificarse con/en ellas.

Pero qué aparece, cuando se pide a los profesores que hablen de las culturas juveniles:

Música, efímera, Poder, Identificación, Diversidad, Búsqueda, Experiencias, Vínculos, Incomprensibles, Escape, Amigos (Colegio Particular).

Manifestaciones colectivas, Desconcierto, Globalización, Modas, Copias, Grupos, Expresiones, Variedad de expresiones, Identidad, Medios de comunicación, Buscadores de identidad, Un lugar de encuentro (Colegio Subvencionado).

Como se ha visto en el apartado anterior, una de las características que señalan los profesores respecto de los jóvenes es la soledad, que se conecta inmediatamente con temas afectivos. Un eje interpretativo que emerge, es que estas formas de sociabilidad son efectos de esa situación: la falta de afectividad. Entonces, las culturas juveniles pueden ser vistas como los espacios donde los jóvenes pueden sentirse acogidos y recrear los afectos perdidos.

Los conceptos de «lugar de encuentro», «vínculos», «amigos» precisamente refieren a eso. La construcción de nuevos espacios de socialidad necesarios para revitalizar los vínculos afectivos, si se acepta el diagnóstico que las instituciones tradicionales dadoras de sentido, hoy en día están en crisis.

Por otra parte, hay otro grupo de conceptos como «globalización», «modas», «copias», «variedad de expresiones», que hacen referencias a culturas juveniles internacionales que han sido adoptadas por los jóvenes. Subyace en estos discursos la idea de una apropiación que remite solo a moda, a imitaciones por lo tanto en cuanto tales, son cosas pasajeras, efímeras, o sea, mera recepción sin contenido crítico, por lo tanto desechables.

Un tercer grupo de conceptos, refiere a entender las culturas juveniles como espacios de construcción de identidades, de experiencias, pero que desaparecen cuando transitan a la adultez: 
[...] esta identidad efímera que pueden fomentar muchas veces, pero que se difumina una vez que entienden cómo se desarrolla todo este proceso de maduración (Colegio Subvencionado).

Hasta ahora, se puede decir, que hay un cierto conocimiento de las culturas juveniles por parte de los profesores, pero a nivel muy general. Son capaces de identificar algunas de ellas por sus experiencias de contacto al interior de los establecimientos educacionales, particularmente por los trabajos que hacen los alumnos en algunas asignaturas cuando se da eso, o por visualización directa en la escuela.

Tomando como ejemplo una cita de profesores de colegios municipalizados, es posible ver cómo los docentes describen no solo lo que comúnmente se conoce como culturas juveniles en su sentido más clásico, sino que también usan el concepto para identificar a otras manifestaciones culturales que son comunes hoy en día, como es el caso de flaites, peloteros, drogos, choros, entre otros.

Por ejemplo [...] están los ocultistas, los que le gusta la onda de las ciencias ocultas, yo no sabía que existían; aquí tenemos grupos hiphop, de la animación [japonesa] que no los conocía tampoco. Están los que son peloteros; los flaite también por así decirlo.

Claro.

- Pero sí es verdad, los que son más choros, así los que se juntan ellos y son los que se podría decir lideran en cierto modo.

- Los drogos, ah, bueno, ese es otro grupo [...]que son bastante mayoritario ahora (Colegio Municipalizado).

Sin embargo, habría que señalar, que si bien existe algún grado de identificación, aunque es menor, los profesores no intentan tener un acercamiento a esas culturas, no se involucran con ellas. Solo se dedican a observar, pero no a interactuar, lo cual implica mantener una distancia con aquello que se observa. Si bien, reconocen que a nivel de conversación se puede interactuar, pero esto no supone un involucramiento mayor, o sea, un acceso a ellas, única forma de conocerlas.

[...] porque no es lo mismo involucrarse en el sentido de conversar con el alumno, a entender realmente cuál es su cultura, me explico, yo puedo mirar desde afuera todos los cabros que son góticos pero yo no me he adentrado en su cultura, puedo conocer a lo mejor a los grupos, puedo conocer los gustos, la, la vestimenta, todo pero yo no participo 
de esa cultura, yo no me adentro y creo que somos muchos los profesores que efectivamente nos sucede eso (Colegio Municipalizado).

[...] uno ya tiene una cultura definida y por lo tanto lo único que uno puede hacer es observar lo que son las otras culturas pero siempre desde afuera (Colegio Subvencionado).

Se puede cerrar este apartado, señalando que los profesores reconocen que los jóvenes traen un tipo de cultura, un conocimiento, que se sitúa paralelo a la cultura escolar, que quizás tiene mayor influencia que otras culturas, pero que como se ha señalado anteriormente, no encuentra recepción entre los profesores.

[...] nosotros partimos de la base de que esta es una socialización secundaria, la del mundo escolar, ellos ya vienen con un conocimiento, nosotros les estamos entregando otro tipo de conocimiento que se fusiona con el conocimiento cotidiano que ellos traen, necesariamente la incidencia mayor de la cultura que ellos tienen no es nuestra, ya, necesariamente tiene que ser de afuera, porque nosotros en que incluimos, por ejemplo, es más, yo haría una autocrítica y diría que yo tiendo a no meterme, ya, en, en, en lo que es su cultura, o sea, tiendo a no meterme, a no adentrarme, a no inmiscuirme (Colegio Subvencionado).

Habría que señalar que no hay una negativa explicita a involucrarse con las culturas que portan los jóvenes que son alumnos de los profesores, pero como ellos señalan que,

[...] los profesores están por su lado y los alumnos por otro, y además que los profesores también discriminamos (Colegio Municipalizado).

\section{UNA CULTURA ESCOLAR AUTORREFERIDA}

No deja de ser revelador observar las conceptualizaciones que tienen los profesores respecto de la denominada cultura escolar. Una primera cosa que queda de manifiesto, es que los profesores señalan que todos los sujetos son portadores de cultura.

[...] todas son culturas, todas son culturas. Unas son más conservadoras, tradicionales, otras son más liberales, otras son más de avanzadas, pero, todos tienen una cultura (Colegio Subvencionado). 
Respecto a la identificación de actorías en la cultura escolar, reconocen que sus componentes involucran a todos aquellos que participan en el espacio escolar...

son varios actores los que participamos: la familia, los profesores, los alumnos, los co-docentes, administrativos, todos los que componen la comunidad escolar (Colegio Municipalizado).

Habría que señalar introduciéndose con mayor profundidad al concepto en cuestión, que los docentes asocian el concepto de cultura escolar con las reglas, hábitos y la socialización. Así, cuando se les pide que indiquen conceptos que estarían asociados a esa cultura, aparecen Cultura, Norma, Sistema, Hábitos, Contención, Reglas, Disciplina, Sociedad entre otros. Del mismo modo, las autopercepciones de los profesores a nivel conceptual supone recurrir a conceptos como: Guía, Dureza, Educativo, Modelo, Compañero, Amigo, Egocéntricos. Como se puede apreciar, un amplio espectro conceptual, que como un péndulo transita desde al amigo/guía al egocéntrico/duro.

Dos cosas resaltan con fuerza entre los profesores respecto de la cultura escolar. La primera es identificar a la cultura escolar como un agente «culturizador». Lo segundo identifican a la cultura con una función determinada: formar a las personas para que tengan una buena inserción social.

Así, la cultura escolar (colegio) es la «antesala» para que los estudiantes alcancen su madurez, cuestión que debería manifestarse en la acción de desvestirse de la cultura que porta como joven y adoptar/vestirse con esta otra cultura, aquella que le permitirá transitar en la sociedad como un sujeto útil, maduro socialmente.

El colegio es básicamente un agente culturizador. Por lo tanto, el chico tiene, debiera salir, con las condiciones más que básicas, para poder convivir con el resto de la sociedad. No con su círculo más cercano, no con su barrio. Porque el día que salga a trabajar, por ejemplo, tiene que ser responsable, tiene que ir bien vestido, ojalá con un buen corte de pelo [...] sin aro [...] porque esas cosas no son aceptadas en el mundo de los adultos y el trabajo (Colegio Subvencionado).

[...] yo también pienso que la cultura escolar, es como, como la antesala de la persona a su madurez. Dependiendo de cómo se manifieste en su entorno escolar, va a ver cómo se desarrolla en un ambiente ya maduro, adulto ya sea laboral o de educación superior (Colegio Subvencionado). 
Es así, que los profesores y la escuela tiene la misión de influir en el desarrollo de los jóvenes, para que maduren, adquieran hábitos y se socialicen de buena forma. De esta forma, aparece el profesor como un formador de personas que tiene como objetivo que sus alumnos puedan ingresar al mundo adulto. En el fondo hay que «armar/construir un sujeto», tal como se arma una máquina.

Se está entonces, frente a un proceso de imposición de una forma de cultura, en este caso la cultura escolar. Si bien esto no aparece nítidamente en los profesores de los colegios particulares y municipalizados entrevistados, implícitamente sí está. Hay que señalar que en el colegio particular subvencionado esto aparece con fuerza, como se aprecia en la siguiente cita:

La escuela tiende a imponer su cultura independiente de la cultura que ellos traigan de la casa. Cuando ellos entran al colegio, ellos asimilan la cultura nuestra, que tenemos como institución, independiente que afuera sean punk, sean cualquier cosa. Y eso es lo bueno, de los alumnos nuestros. Así, a la larga uno logra insertar al alumno a la cultura que nosotros queremos, y tú los ves acá adentro, los ves que ellos se desenvuelven, con el reglamento de convivencia que nosotros tenemos (Colegio Subvencionado).

Esto supone, que ante la diversidad de jóvenes y culturas que podrían manifestarse, los profesores del colegio particular subvencionado, piensan que el colegio debe tener una clara postura, a saber, de no permitir la manifestación de éstas dentro del establecimiento educacional.

Ahora, esta posición se presenta con una argumentación que parece muy lógica: permitiría realizar un mejor trabajo de inculcación de ciertos aspectos normativo y valóricos, que precisamente en opinión de los docentes no cuentan sus alumnos y que les permitiría funcionar mejor en los distintos espacios que constituyen la sociedad. Sin embargo habría que señalar, que los profesores del colegio subvencionado son realistas respecto de esta lucha cultural, ya que saben que no es posible en un ciento por ciento impedir el paso de las culturas juveniles al espacio escolar. Esto supone entonces, que se implemente una estrategia para que la cultura escolar, que está depositada en el proyecto educativo y valores propios del colegio, sea más fuerte que esas otras culturas que portan los jóvenes. 
Sería más fácil para nosotros trabajar con un mismo tipo de alumno. Pero, entendiendo que eso es prácticamente imposible, resulta mucho más beneficioso para nosotros y a la vez, proponer un mayor énfasis en que la cultura escolar sea más fuerte, que la que está en el exterior. Pese a las múltiples manifestaciones que existan, entonces reforzar, estos valores, todo este proyecto educativo, en definitiva, tiene que ser muy superior a todas estas tribus urbanas, o cierta ambigüedad en definitiva que los jóvenes tienen con su propia ambivalencia (Colegio Subvencionado).

Una estructuración del espacio cultural del colegio donde se invisibiliza y controla las otras culturas, trae grandes beneficios al colegio. Como señalan los profesores del colegio subvencionado, en un colegio construido de esa forma, no habría transgresiones de las normas, que se visibilizan en los colegios a través de las peleas u otro tipo de agresiones por ejemplo, lo cual está directamente relacionado con problemas de disciplina.

Esta forma de entender la cultura escolar, obviamente que trae aparejado otras cosas. Por ejemplo, los profesores del colegio particular señalan, que producto de la disciplina imperante los estudiantes tienen poco espacio de maniobra cuando tratan de organizarse, particularmente en coyunturas de movilizaciones estudiantiles.

Los profesores son claros. A los alumnos del colegio se les escucha poco. Sus organizaciones son solo cosméticas ya que se encuentra al arbitrio de las autoridades del colegio, las cuales ejercen censura sobre las actividades estudiantiles. En el fondo, las autoridades, no tanto los profesores, intentan construir un «colegio burbuja», o sea, que no está o no se deja permear por los acontecimientos que ocurren en la sociedad.

O sea a mí, personalmente me llamó mucho la atención, que a raíz de todo esto que está ocurriendo en nuestro país, en todas las protestas, hay aquí un centro de alumnos al que no se le escucha lo suficiente, que existe cosméticamente, en el que los chicos están muy censurados. Hay cosas que no se permiten, y no se permiten nomás. Sí, muy censurado. $\mathrm{O}$ sea no tenemos libertad en ese sentido. Tenemos que, hay una cabeza, y tenemos que obedecer a esa. Por lo tanto la cultura escolar de este colegio es una burbuja (Colegio Particular).

Evidentemente que toda esta situación genera tensiones culturales al interior del espacio escolar que se vive como un «choque cultural». Si bien, este tipo de situación no se enuncian claramente entre los 
profesores. No obstante, en uno de los colegios, es graficado como una situación que deja al joven, en un constante tránsito entre estas culturas, sin pertenecer por completo a una de ellas, donde se asume además, que la cultura escolar, en la que se considera un modelo aceptable a seguir.

[...] esto provoca el choque entre las culturas. A la larga, o a la corta, termina chocando con las culturas tradicionales, por decirlo así. Y una institución educativa, tiene una cultura más tradicional. Hay un marco de acción, en el cual todos interactuamos, todos los agentes que están en el colegio, los alumnos, los docentes, los auxiliares [...] y todos nos regimos por eso. Y a los chicos, que están en ese tipo de situaciones, por esa falta de desarrollo valórico, tienden a chocar con esta reglamentación, que hoy por hoy se llama convivencia escolar (Colegio Subvencionado).

\section{A MODO DE APERTURA REFLEXIVA}

El análisis de la información recogida en el estudio, nos permite elaborar de forma general algunas reflexiones que pueden ser objeto de discusión para estudios posteriores.

\section{a) Prejuicios juveniles y la cuestión de género}

Una primera cosa que resalta en los profesores, refiere a los «prejuicios juveniles y la cuestión de género». Los discursos analizados, nos muestran que los profesores tienen una serie de prejuicios sobre los jóvenes que transitan de forma pendular, desde prejuicios positivos hasta negativos: «joven incomprendido», «joven carenciado», «joven ego» y «cabro chico con carencia afectiva», pero también conceptos como «capaces», «aperrados», «críticos», «inteligentes», entre otros.

De interés es destacar en este punto, el prejuicio de género que aparece en los discursos relacionada con las mujeres jóvenes. Es una aparición por deficiencia, o sea, es aquello que no se dice discursivamente pero que provoca una distinción. En las entrevistas realizadas, aparece de forma espontánea, referido al tema de la pérdida de valores y la sexualidad de las mujeres jóvenes. Hay una construcción de una mujer joven que transita por la vida con una vida sexual activa, cuestión que preocupa bastante a los docentes, y que tiene relación con las construcciones de ser mujer hoy. 
Sin embargo, en las entrevistas no aparece nada relacionado con los hombres respecto de este tópico: la vida sexual. Es interesante esto, ya que permite visualizar, como ciertas prácticas son prejuzgadas según el género. Así, los «reproches» sobre la vida sexual van dirigidos a las niñas, pero no a los varones. Al parecer, la cultura machista está muy bien instalada y subyace discursivamente, una baja tolerancia al desborde de las mujeres, pero no así, al desborde de los hombres.

\section{b) No existe desde el profesorado una visión clara de lo que son las culturas juveniles}

Una segunda cuestión que se manifiesta, es que no existe desde el profesorado una visión clara de lo que son las culturas juveniles. Para muchos estas culturas son vinculadas con prácticas, actitudes y valores no deseados, que se contraponen a la lógica de la llamada «cultura escolar». Solo en el último tiempo y gracias a una mayor difusión de éstas principalmente a través de hechos noticiosos, algunos profesores se han acercado un poco más a identificarlas, pero casi siempre desde una mirada normalizadora cercana al estigma en muchos casos. Los intentos de adaptar las expresiones de estas culturas juveniles a la cultura escolar, supone un entendimiento de estos, como un sujeto más bien homogéneo, que se puede unificar bajo un solo rótulo: el de ser estudiante o escolar, cuestión que no da cuenta de este sector importante de la población, que precisamente se caracteriza por su diversidad. Esto explicaría muchas veces la naturaleza eminentemente coercitiva de algunas de las decisiones que toman los profesores.

Así, se diseña un cuadro donde por un lado se trata de adaptar el sistema educacional a la lógica global de transformación sociocultural, pero, por otro, se trata más bien de adaptar el producto de estas transformaciones; es decir, el estudiante, al mundo educativo en general y a la cultura escolar en particular. Se detecta a partir de estas estrategias una dualidad en términos de una orientación integradora y otra impositiva.

En su conjunto, estas iniciativas buscan aproximarse al joven, o «comprenderlo» según se señala, para después atraerlo a la realidad escolar; es decir, retenerlo en ella. Se trata, por tanto, de estrategias pensadas desde una mirada eminentemente adultocéntrica e ilustrada, a pesar de que en algunas de ellas los estudiantes aparecen como 
protagonistas. Esto probablemente pueda explicar que desde los jóvenes sigan existiendo reacciones de desinterés o apatía ante las nuevas propuestas educativas. De allí el desafío de conocerlas y comprender sus lógicas no solo buscando reducir ciertas tensiones que se generan entre profesores-alumnos sino que también buscando elementos motivadores que logren enganchar a los jóvenes con su espacio educativo.

\section{c) El profesor nunca ha sido joven}

Una tercera cuestión que emerge, es la imagen de que el profesor nunca ha sido joven. La lectura de las entrevistas arroja un aspecto de por si interesante. Los profesores no pueden o no quieren conectarse con sus estudiantes; en muchos casos no pueden empatizar con ellos. ¿Cuál podría ser la razón de esto?

Una línea interpretativa es que esta desconexión es fruto de la incapacidad de los profesores de conectarse con sus experiencias juveniles. De hecho, dejan de lado sus experiencias y no las utilizan a la hora de relacionarse con los jóvenes. Hay al parecer un dejo de vergüenza, de mostrar que alguna vez se tuvo una edad similar a sus estudiantes, lo cual supone recordar situaciones donde en más de alguna oportunidad se habría transgredido el orden normativo tal como lo realizan sus alumnos hoy en día.

Si estas evocaciones del pasado juvenil se pusieran en circulación, supondría hacer parte a los estudiantes de la memoria juvenil que porta el docente. Como esto no es de interés en los docentes, se oculta. Entonces, el profesor nunca fue joven; es el viejo, aunque parezca joven. El ocultar la experiencia juvenil, al parecer tiene que ver con no perder el sitial y rol que tienen los profesores al interior del espacio educativo. También para no verse interpelados por lo estudiantes frente a situaciones complejas.

Sobre este punto habría que señalar que el profesor siempre será «el viejo». Algunas observaciones y conversaciones registradas nos muestran que profesores jóvenes, que deberían poder conectarse mucho mejor con sus alumnos, independientemente de las brechas generacionales existentes, no logran empatizar con sus alumnos. Pisan la escuela, o sea, atraviesan la reja que separa a la escuela de la comunidad y se vuelven profesores. Este mismo ejercicio, pero de manera inversa, es lo que la escuela hace con los jóvenes: cruzan la reja de la escuela y sus atuendos culturales son dejados de lado; no 
pueden cruzar la reja. La mochila cultural que cargan - porque cargan varias mochilas-, no es para llevarla a la escuela, porque ella es celosa de otras culturas y entonces, se vuelven estudiantes, alumnos o escolares, dejando de ser jóvenes. Ambos, profesores y jóvenes, aprenden un oficio. Los primeros, aprenden el oficio de profesor que no se sacaran más y donde las transgresiones están prohibidas o se reprimen. Los segundos, aprenden el oficio de ser alumno, lo cual supone realizar un ejercicio continuo de transgresión.

Por otra parte, cuando los docentes llegan a conectarse con sus vivencias juveniles. La utilizan para ser la matriz de evaluación de prácticas, conductas u otras manifestaciones juveniles que se dan en la escuela. Se evoca entonces por parte del profesor «todo tiempo pasado fue mejor». Por lo tanto, mi juventud fue mejor a la que actualmente viven los jóvenes, porque precisamente hay un diagnóstico elaborado por parte de los profesores que se está frente a una juventud falta de valores y normas.

No menor es otro tipo de evocación que se relaciona con «la envidia». Como señalaban algunos de los profesores entrevistados, los jóvenes actuales tienen acceso a cosas que ellos no tuvieron; hacen cosas que ellos no pudieron o no quisieron hacer. Por lo tanto, envidian una juventud mucho más abierta, transgresora que aquella que les tocó vivir, pero que sin embargo no la evaluarían mal.

\section{d) Metáforas de la escuela}

Un cuarto tópico, dice relación con ciertas metáforas de la escuela que se desprenden de los discursos de los profesores. Originalmente, la escuela se constituyó como un espacio separado de la sociedad, con un rol bastante específico: formar subjetividades que pudieran insertarse correctamente en la sociedad. Este espacio fue visto en algunos momentos como la reserva moral de la sociedad, donde se entregaban un conjunto de valores, normas y «virtudes», que hacían que los sujetos fuesen sujetos sociales plenos. Frente a las vicisitudes por la cuales podía atravesar el mundo, la escuela se erigió entonces como el «faro que iluminaba el mundo». Está metáfora es interesante, ya que remite también a otra. En cuanto faro y espacio que ilumina, supone que hay algo que iluminar, por lo tanto se construye en oposición a algo que es oscuro. Entonces, la escuela se ubica en contraposición a la sociedad que sería el espacio de la barbarie. Lo civilizado entonces es la escuela. 
Otra metáfora es visualizar a la escuela como un «espacio sagrado». Tenti (2008) señala respecto de este punto que la escuela se constituye como un mundo separado, reivindicando su carácter de sagrado, a través de su cultura y valores, los cuales son puestos por sobre la cultura y valores que transitan en la sociedad. Así la escuela se visualiza a salvo de las influencias de la sociedad, mejor dicho de las malas influencias. Esto fue la escuela en sus inicios. Aquella escuela que se construyó bajo la lógica del santuario y donde las salas de clases son los templos, lo cual supone una particular dinámica de habitar esos espacios. Sin embargo hoy en día ha perdido ese carácter de sagrado y por lo tanto se ve expuesta a la contaminación del mundo, contaminación que tiene como vehículo privilegiado a los jóvenes y sus culturas. La escuela como santuario y el aula de clase como templo.

Habría que señalar que en los discursos de los docentes aparecen de forma muy nítidas estas ideas, especialmente cuando intentan defender el espacio de la escuela para que se mantenga a salvo de la contaminación exterior, que no son más que las expresiones culturales que portan los jóvenes. Así, la escuela y el espacio del aula es normalizado, se entiende como orden, como silencio, sin movimientos lo cual se transforma en el clima adecuado para generar aprendizaje.

SANTIAGO (CHILE), OCTUBRE 2013

RECIBIDO: OCTUBRE 2013 ACEPTADO: DICIEMBRE 2013

\section{REFERENCIAS BIBLIOGRÁFICAS}

Benavente, Carolina y Griselda Figueroa (2005): «La deserción simbólica. Cultura juvenil y educación: perspectivas para un diálogo pendiente». Documento de Discusión. Santiago: CESC.

EDWARD, VERÓNICA (1995): «El liceo por dentro. Estudio etnográfico sobre prácticas de trabajo en educación media». Santiago: Ministerio de Educación de Chile, Programa Mejoramiento de la Calidad y Equidad de la educación.

MARTÍN-BARBERO, JESÚS (1998): «Jóvenes: des-orden cultural y palimpsestos de identidad». En: Humberto Cubides, María CRISTINA LAVARDE y CARLOS VALDERRAMA: Viviendo a toda, jóvenes, territorios culturales y nuevas sensibilidades. Santafé de Bogotá: Universidad Central-DIUC. 
MARTÍN-BARBERO, JESÚs y GERMÁN REY (1999): Los ejercicios del ver. hegemonía audiovisual y ficción televisiva. Barcelona: Gedisa.

REguiLlo, Rossana (2000): Emergencia de las culturas juveniles. Estrategias del desencanto. Buenos Aires: Editorial Norma.

TENTI, EMILIO (2002): «Culturas juveniles y cultura escolar» Disponible en://www.pedagogica.edu.co.

VALENZUEla, José MANUEL (2004): «Culturas identitarias juveniles». En: Reguillo, FeIXA, VALdeZ, GoMeZ-Granell y PÉrez Islas: Tiempo de híbridos. Colección JOVENES N¹4. México: IMJ.

ZARZURI, RAÚl y RODRIGO GANTER (2005): Jóvenes: la diferencia como consigna. Ensayos sobre la diversidad cultural juvenil. Santiago: Ediciones CESC. 